\section{Systemic Gifted Education: A Theoretical Introduction}

\author{
Albert Ziegler' and Heidrun Stoeger ${ }^{2}$
}

Gifted Child Quarterly

2017, Vol. 6I(3) 183-193

(C) 2017 National Association for

Gifted Children

Reprints and permissions:

sagepub.com/journalsPermissions.nav

DOI: $10.1177 / 0016986217705713$

journals.sagepub.com/home/gcq

(S)AGE

\begin{abstract}
Over the past few decades, systemic thinking has gained in popularity in developmental and learning sciences. The trend has, however, shown up in gifted education research only occasionally. The aim of this article is to introduce systemic thinking to the field of giftedness and explore possibilities for its application. In the first part, a definition of a system is provided and basic concepts of systemic thinking are introduced. In the second part, a full-fledged systemic model is introduced, the actiotope model of giftedness. In the third part, implications for gifted education are elaborated. In the discussion, the authors explain (a) how systemic thinking can make a valuable contribution to gifted education, (b) why systemic thinking will complement rather than replace current approaches to gifted education, and (c) the necessity of combining systemic thinking with other empirically testable theories.
\end{abstract}

\title{
Keywords
}

systemic gifted education, actiotope, educational capital, learning capital

Since about 1990, a new type of thinking has attracted the attention of an increasing number of scientists interested in the investigation of human development and learning (e.g., Richardson, 2013; Thelen \& Smith, 1994). Systemic thinking is concerned with the simultaneous investigation of many variables and their changes over time as well as self-organizations into states with radically different properties. It has been applied to a wide variety of fields including economics, biology, ecology, psychology, and education (e.g., Luenberger, 1979; Michel, Wang, \& Hu, 2001). Its basic assumption is that many aspects of reality can be better analyzed as interconnected elements or components that form a whole or an entirety that acts in a specific environment.

Although some authors in the field of gifted ${ }^{1}$ education include systemic thinking and various concepts from systems approaches in their work (Csikszentmihalyi, 1998; Dai, 2009; Ziegler, 2005; Ziegler \& Phillipson, 2012b), this is still the rare exception. However, given the recent rise in popularity of systemic thinking in developmental and learning sciences, systems approaches will likely become more important in gifted education, too (Ziegler \& Phillipson, 2012a).

Should this expectation come to fruition, the field will face two issues: First, systems theory is not a clear-cut theory, but constitutes a family of theories including diverse approaches. Thus, systemic thinking can be introduced into the field of gifted education in numerous forms. The variant we describe here was chosen with regard to the particularities of the field of giftedness and is based on the actiotope model of giftedness (AMG; Ziegler, 2005).

Second, one will then wonder what role systemic thinking will play among already established approaches of gifted education. Will it enter the field as a rival paradigm that seeks to replace existing approaches, or will it enter as a complementary perspective that offers new, complementary insights and can be combined with existing approaches? In this article, we argue for the latter. We argue that systemic thinking can - indeed needs - to be organically combined with existing conceptions of giftedness. It will fill important gaps and help existing approaches become more effective and relevant.

\section{Definition of a System}

No consensus exists about a formal definition of what constitutes a system. In his classic definition, biologist Ludwig von Bertalanffy (1975) wrote that a system is a "set of elements standing in interrelation among themselves and with the environment" (p. 159). In his definition, developmental psychologist Willis Overton (2013) adds the two important aspects of wholeness and function and defines a system as "a whole which functions as a whole by virtue of the interdependence of its parts" (p. 54). Similar definitions have been suggested, but none of them is, in our view, ideal for giftedness research and gifted education. For example, Overton's

\footnotetext{
'University of Erlangen-Nuremberg, Nuremberg, Bavaria, Germany

${ }^{2}$ University of Regensburg, Regensburg, Bavaria, Germany

Corresponding Author:

Albert Ziegler, Department of Psychology, Chair of Educational Psychology and Research on Excellence, University of ErlangenNuremberg, 90478 Nuremberg, Bavaria, Germany.

Email: albert.ziegler@fau.de
} 
(2013) definition fails to consider the important role of resources (Ziegler, Chandler, Vialle, \& Stoeger, in press), which we discuss below. Thus, we suggest the following definition of a system: A system consists of interacting elements or components that make use of resources to maintain a certain level of internal stability and function as a whole in order to produce certain behaviors.

From the perspective of gifted education, such a definition raises several issues such as, for example, the question of what the "certain behaviors" are. However, before we apply this definition to gifted education, we first make a number of necessary preliminary remarks on the general meaning of the constituent parts of the definition.

\section{Elements and Components}

A system consists of elements that are organized into components. Elements are the smallest building blocks that can be captured with the theoretical language of an observer who is describing a system. Components consist of elements or subsystems and are thus, by definition, suprasystems.

When analyzing a system, the resolution level is not fixed and can range from the element level to the highest order of suprasystems. The chosen resolution level is ultimately dependent on the purposes of the observer. For example, should a research question be focused on the best possible diet for a talented ultramarathon runner, the level of resolution would be at the organismic level. However, the resolution level would be at the group level when the bullying of a gifted student is the focus.

\section{Is Everything a System?}

An interesting question is whether all collections of elements are systems. Indeed, the simple answer is no. According to the definition of a system provided above, simple collections of noninteracting elements and components do not create systems. For example, when a child makes her very first basket in basketball, this might remain a singular event for a long time. Bystanders may not even notice the basket let alone praise the child for her good aim, and the child's attention might immediately move on to something else. Thus, in this hypothetical instance, with regard to the domain of basketball, no components can be isolated that are interacting to produce stable behavioral patterns.

Pure collections of elements or components are usually termed a set. Sets, of course, might develop into systems, and that is exactly what happens when an individual lives up to her or his talents, as we see below.

\section{Interaction of Elements}

In current models of giftedness, two types of interactions dominate. The best-known type of interaction is the additive interaction. For example, in Renzulli's (1986) influential three-ring model, giftedness is the result of above-average cognitive abilities, creativity, and task commitment. In contrast, Simonton (2005) pointed out that talent development might be better described by multiplicative interactions, as a multiplicative relationship better captures the fact that when necessary factors are missing - such as environmental support-talents cannot be developed. Systemic thinking adds three more interaction types (Ziegler, 2005): negative feedback loops, positive feedback loops, and coevolutions.

Negative feedback loops describe the phenomenon in which the output of a system feeds back into the system in a way that promotes equilibrium. In contrast, in a positive feedback loop the output of a system feeds back in a way that increases input and, in turn, the output of the system. In negative feedback loops behavior frequency decreases; in positive feedback loops the frequency of behaviors increases. Negative feedback loops have frequently been postulated to explain human development and learning. They are the key mechanism in the concept of equilibration suggested by Piaget (1960) or in the TOTE model (test-operate-testexit) suggested by Miller, Galanter, and Pribram (1960). There are also many well-known examples of positive feedback loops. One example is that of a student who finds himself caught in a downward spiral of failure. The initial failure might cause negative emotions that, in turn, lead to another failure, which, in turn, leads to additional negative emotions, and so on (Pekrun, Lichtenfeld, Marsh, Murayama, \& Goetz, 2017). As increases cannot continue forever, positive feedback loops are not stable.

A third type of interaction are coevolutions (Ziegler \& Phillipson, 2012b). They describe processes in which the changes in one component of a system cause other components of the system to adapt to this change and to synchronize. In extreme cases, the whole life of an expert can be dedicated to her field of expertise.

\section{Wholeness}

A set is usually studied by breaking it down into its constituent parts and trying to understand their properties. The whole can then be described as the sum of its parts. This approach is termed reductionism, and its main method is the analytic method. Not only is reductionism the dominant approach in models of giftedness (see Sternberg \& Davidson, 2005) it has also been the main approach of modern Western science since the Renaissance and has been extremely successful (Nisbett, 2003). It works very well when there is a low level of connectivity and interdependency among the constituent parts. However, if one is primarily interested in relationships between the components and their joint function, then a holistic approach can provide further insight. Indeed, many systems have a high level of interconnectivity and are even mainly defined by the relationships among their components (ecosystems, social systems, etc.). The main method of holism is synthesis. It tries to give an answer to the question 
of how components form an integrated whole or a functioning entity and what their dynamics are.

\section{Internal Stability}

In considering the makeup of systems, two processes have to be distinguished. The process in which a system returns to a particular state is homeostasis. A well-known example is the digestive system. Homeorhesis, on the other hand, is the process in which a dynamical system returns to a trajectory. For example, a talent might have had a setback in her learning. Her teacher encourages her and brings her back on her learning pathway.

\section{Resources}

Resources are means to an end. They are the input to the internal processes of a system. If they are entering the system from its environment, they are termed exogenous resources. If they have been stored in the system itself, they are termed endogenous resources.

\section{Behavior of the System}

Systems are specialized to interact with some parts of the environment in specific ways in order to maintain their integrity or to build resources. From a systemic perspective, humans are self-organizing systems that are capable of carrying out many behaviors to the ends of maintenance, regulation, and development.

\section{The Actiotope Model of Giftedness}

The AMG has been described numerous times over the past 12 years (Ziegler, 2005), and numerous detailed accounts can be found in the research literature (e.g., Ziegler, Stoeger, \& Balestrini, in press; Ziegler, Vialle, \& Wimmer, 2013). Here, we focus on elaborating the theoretical aspects of the model that are most important for its application in gifted education.

\section{The Target of Gifted Education}

A system is a model and, as such, does not provide a full description of a part of reality. The observer must decide what will, and what will not be included in a model. Obviously, an individual can be analyzed on many levels, for example, from the perspectives of physics (e.g., weight), biochemistry (e.g., production of adenosine triphosphate from glucose), or psychology (e.g., stress regulation). In the AMG, the focus (Ziegler, 2005) is on actions (e.g., walking, thinking, singing, baking bread, sequencing genes, designing computer games, writing a novel, etc.). An actiotope is defined as the entirety of the individual and its material, social, and informational environment with which the individual interacts (Ziegler et al., 2013). Thus, the target of systemic gifted education based on the AMG is much broader in scope than the target of traditional gifted education, which focuses mainly on the individual. Indeed, a gifted educator working within the systemic paradigm of the AMG aims to develop the whole ecology of an actiotope.

\section{Systems Addressed in the AMG}

There are three categories of systems addressed in the AMG: systems not directly connected to talent development, systems directly connected to talent development, and the actiotope itself, which, under certain conditions, can also be understood as system.

In the AMG, the fact is acknowledged that an individual is embedded both in many systems and in suprasystems not directly connected to talent development. Examples of suprasystems encompass family, circles of friends, or the healthcare system. Similarly, the individual is a suprasystem to numerous subsystems such as its motivational system or respiratory system. All these systems are, in one way or another, indirectly important for talent development (and can also sometimes change into a system that is directly connected to talent development). However, to which of these many systems a gifted educator pays attention depends on the specific educational interest at hand.

Of special importance for gifted education are all systems that are specialized on fostering talent development either directly (e.g., kindergarten, school, university, sports teams, athletics clubs, summer schools) or indirectly (e.g., advocacy groups, foundations offering scholarships, organizers of international competitions). Systems linked both directly and indirectly to talent development can be analyzed from various angles. First and foremost, it is important to know how well each system fulfills its designated functions. For example, how effective is a teacher at instructing her gifted students. Second, systemic thinking is interested in the interactions of systems. The most important question here is whether interactions of systems produce synergies (i.e., a larger output than the sum of the outputs of each system) or interferences (i.e., less output than the sum of the outputs of each system). For example, an exhausting physical education class in the morning at school might interfere with athletic training in the evening due to insufficient recovery time. On the other hand, imparted school contents can also be beneficial for the understanding of the content of special enrichment courses and as such contribute to a synergy.

A crucial question is whether an actiotope itself is a system. In light of the definition of a system, the answer depends mainly on three crucial conditions: (a) whether the components interact as a whole to produce, (b) certain outcomes, and whether (c) the actiotope achieves homeostasis or homeorhesis while producing this behavior. If, for example, a young girl plays one game of chess, it can hardly be said that her actiotope is a system that produces more and more 


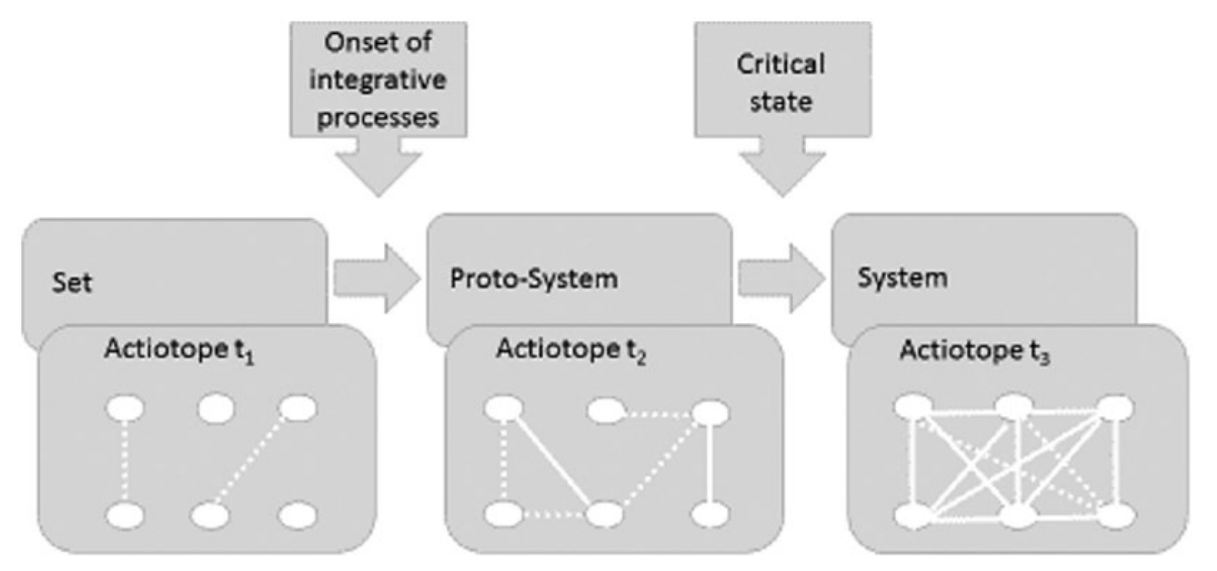

Figure I. Three phases in development of an actiotope into a system. Note. Dotted lines symbolize an established relation, solid lines symbolize mutually stabilizing and reinforcing relations. The abbreviations $t_{1}, t_{2}$, and $t_{3}$ refer to different points in time.

chess activities. However, if we analyze the everyday behaviors of a chess master, we see that almost every activity in her life is dedicated to chess-including her sleeping habits, nutrition decisions, and athletic activities. She has many books on chess on her bookshelves; and a considerable portion of all her utterances is related to chess. Thus, when talent development starts (as might be the case for the girl who plays one game of chess), the actiotope is usually better characterized as a set (in Figure 1, refer to $t_{1}$ ). If the talent is recognized, activities typically become better integrated and a protosystem emerges (Figure 1, $\mathrm{t}_{2}$ ). When an actiotope becomes more developed toward excellence and its components better integrated, it might pass a critical state and become a system (Figure 1, $\mathrm{t}_{3}$ ). Even when facing obstacles and setbacks, numerous mechanisms maintain the actiotope's balance and keep it on target.

\section{Components of an Actiotope}

Reality is always entangled, and this is also true for parts of reality such as actiotopes and their components. We now introduce the four components within an actiotope that are the suprasystems of the highest order and whose joint interplay explain specific actions of an individual. It is important to note, however, that these components can be broken down in subsystems that are also entangled in various ways.

Actions and Action Repertoire. An action repertoire describes all the states a system can produce to attain its goals. Thus, the action repertoire of a person consists of the sum of all theoretically possible actions of which a person is capable. Hence the action repertoire encompasses myriad skills (e.g., performing mathematical operations, motor behavior, verbal behavior such as answering questions, mental operations such as thinking, perceptual actions such as processing auditory information, and emotional responses such as reacting with disgust to certain stimuli).

One of the main aims of education is to provide individuals with effective action repertoires in order to enable them to act competently in modern societies. At school, for example, the action repertoire of a student gradually expands, encompassing, at first, only simple mathematical operations such as subtraction and multiplication until, finally, complex operations such as calculus become part of the student's action repertoire.

Gifted education in particular is concerned with individuals who are able to develop extraordinarily effective action repertoires that can, in extreme cases, become as effective as the skills demonstrated in visual arts and music by Michelangelo and Mozart respectively or as effective as the skills in golf and physics demonstrated by Woods and Newton, respectively. In this sense, excellence denotes an extraordinarily effective action repertoire in a domain. With regard to the development of effective action repertoires, we suggest distinguishing four types of actions according to their function, all of which we now describe in turn.

Target actions are the actions a gifted educator is directly aiming at. Their number is literally infinite. A gifted educator can set any educational goal that she deems in the best interest of a gifted individual. These might include learning strategies, failure coping, prosocial behavior, assertive action, and so forth. Of special interest for gifted education are all those actions that can produce direct progress toward higher skill levels or even excellence in a talent domain.

Auxiliary actions are those actions that support target actions. Examples abound: parents drive their children to school; chemistry teachers set up experiments; a gifted student buys stationery for her studying, or commutes to school.

Anticipatory actions serve resource building. Examples include endurance training by a soccer player so she will 


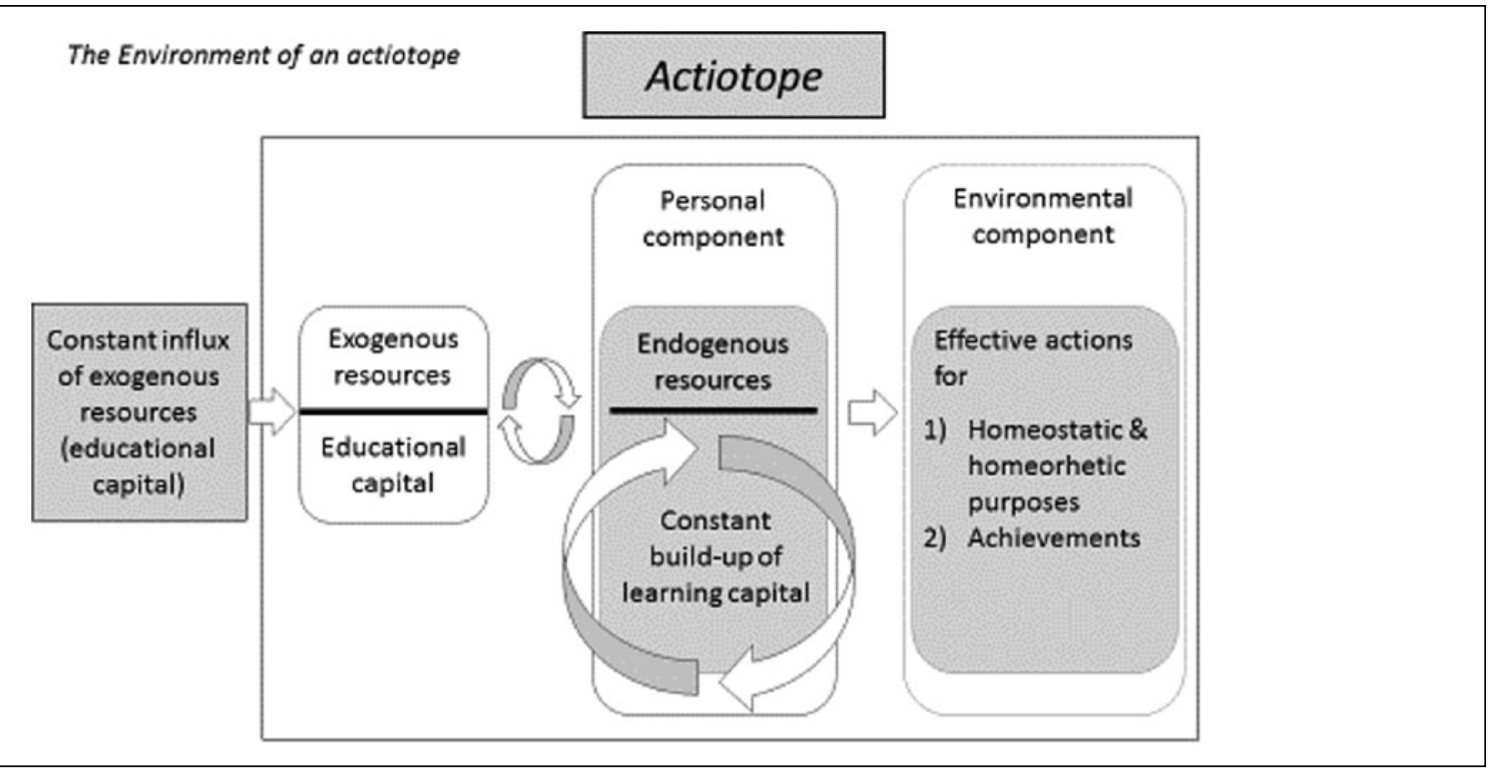

Figure 2. Endogenous and exogenous resources in the actiotope model of giftedness.

have the stamina for longer practices. Similarly, the learning of a foreign language at school might only become truly useful to an individual when on the job, a decade after finishing high school.

Regulatory actions comprise all kinds of actions that aim at maintaining homeostasis or homeorhesis. Examples include phrases used for self-motivation ("I can do it!"), management of self-esteem, adjusting to social contexts, and the use of learning strategies to gain understanding.

Goals. A system prefers some states while avoiding other. This phenomenon is covered in the AMG by the construct of the goals of an individual, which the AMG defines as internal or external states to which an individual aspires (attractors) or which an individual tries to avoid (repellers) by initiating action. For a gifted educator, it is of utmost interest how these preferred states correspond to the various classes of actions introduced above.

Environment. The environmental component of an actiotope consists of the part of the environment with which an individual interacts. It is important to distinguish two views of the environmental component: the objective environment and the individual's representation of the environment. When the component "environment" is addressed in the AMG, it is meant as the objective environment. The objective environment provides both opportunities for and constraints on individual action.

Subjective Action Space. Like the action repertoire, the subjective action space is also a hypothetical construct. In every single situation in life, an individual faces the problem of how to find the most effective action. To this end, the individual must interrelate the other three components of the actiotope. In other words, the individual must decide which action to choose from the action repertoire in the given environment to attain the presently most desirable state or goal. Please note that when describing the subjective action space the environment addressed is no longer the objective environment but rather the enacted environment. In contrast to the objective environment, the enacted environment is conceptualized as a "mental representation embodied in a cognitive structure which is enacted in retrospect and fashioned out of the discrete experiences" (Brownlie, 1994, p. 147). For example, Jones (2012) found among top athletes, CEOs, military leaders, and physicians that superior intellectual performance is not simply having skills but rather also being aware of having these skills and of how to use them. Thus, the subjective action space is fallible in representing the individuals' action repertoire, goals, and environment.

\section{Resources}

We defined a system above as a group of interacting components that process resources in order to maintain internal stability and to produce certain behaviors. As can be seen in Figure 2 , these resources can come from the environment or be situated in the individual. In previous work, an exhaustive categorization of resources has been introduced in which five exogenous learning resources, termed educational capital, and five endogenous learning resources, termed learning capital, are distinguished (Ziegler \& Baker, 2013; Ziegler, Chandler, et al., in press). Table 1 provides an overview of definitions for all 10 types of learning and educational capital.

Without sufficient resources, talent development is impossible. For this reason, the availability and competent use of 
Table I. Definitions of the Educational and Learning Resources.

\begin{tabular}{|c|c|c|c|}
\hline \multicolumn{2}{|l|}{ Exogenous resources } & \multicolumn{2}{|r|}{ Endogenous resources } \\
\hline $\begin{array}{l}\text { Economic educational } \\
\text { capital }\end{array}$ & $\begin{array}{l}\text { Economic educational capital is every kind } \\
\text { of wealth, possession, money, or valuable } \\
\text { that can be invested in the initiation and } \\
\text { maintenance of educational and learning } \\
\text { processes. }\end{array}$ & $\begin{array}{l}\text { Organismic } \\
\text { learning capital }\end{array}$ & $\begin{array}{l}\text { Organismic learning capital consists of } \\
\text { the physiological and constitutional } \\
\text { resources of a person. }\end{array}$ \\
\hline $\begin{array}{l}\text { Social educational } \\
\text { capital }\end{array}$ & $\begin{array}{l}\text { Social educational capital includes all persons } \\
\text { and social institutions that can directly } \\
\text { or indirectly contribute to the success of } \\
\text { learning and educational processes. }\end{array}$ & $\begin{array}{l}\text { Attentional } \\
\text { learning capital }\end{array}$ & $\begin{array}{l}\text { Actional learning capital denotes the } \\
\text { action repertoire of a person-the } \\
\text { totality of actions they are capable of } \\
\text { performing. }\end{array}$ \\
\hline $\begin{array}{l}\text { Cultural educational } \\
\text { capital }\end{array}$ & $\begin{array}{l}\text { Cultural educational capital includes value } \\
\text { systems, thinking patterns, models, and } \\
\text { the like that can facilitate-or hinder-the } \\
\text { attainment of learning and educational goals. }\end{array}$ & $\begin{array}{l}\text { Telic learning } \\
\text { capital }\end{array}$ & $\begin{array}{l}\text { Telic learning capital comprises the } \\
\text { totality of a person's anticipated } \\
\text { goal states that offer possibilities for } \\
\text { satisfying a person's needs. }\end{array}$ \\
\hline $\begin{array}{l}\text { Infrastructural } \\
\text { educational capital }\end{array}$ & $\begin{array}{l}\text { Infrastructural educational capital relates to } \\
\text { materially implemented possibilities for } \\
\text { action that permit learning and education to } \\
\text { take place. }\end{array}$ & $\begin{array}{l}\text { Actional learning } \\
\text { capital }\end{array}$ & $\begin{array}{l}\text { Episodic learning capital concerns the } \\
\text { simultaneous goal- and situation- } \\
\text { relevant action patterns that are } \\
\text { accessible to a person. }\end{array}$ \\
\hline $\begin{array}{l}\text { Didactic educational } \\
\text { capital }\end{array}$ & $\begin{array}{l}\text { Didactic educational capital means the } \\
\text { assembled know-how involved in the design } \\
\text { and improvement of educational and learning } \\
\text { processes. }\end{array}$ & $\begin{array}{l}\text { Episodic learning } \\
\text { capital }\end{array}$ & $\begin{array}{l}\text { Attentional learning capital denotes } \\
\text { the quantitative and qualitative } \\
\text { attentional resources that a person } \\
\text { can apply to learning. }\end{array}$ \\
\hline
\end{tabular}

Note. The definitions are taken from Ziegler and Baker (2013, pp. 27-3I).

resources is a central concern for gifted education. In an upcoming publication, we outline several consequences of a resource orientation for gifted education (Ziegler, Chandler, et al., in press). These include new principles for a better understanding of gifted development. For example, the continuity principle implies that resources need to be available all along the learning pathway. The high dropout rates among the gifted suggest that if the supply of certain resources is interrupted at any point, a gifted individual might easily give up (e.g., Matthews, 2009). Moreover, the law of the minimum states that an actiotope's growth and development are not governed by the total amount of available resources but rather by the scarcest resource among these.

\section{Gifted Education}

In this section, systemic and nonsystemic approaches to gifted education are contrasted. Whereas the analytic method seeks to break down reality into factors, the synthetic method, which is used in systemic approaches, does the opposite. It is interested in patterns, in meaningful ways in which factors are connected. Thus, systemic gifted education is concerned with the identification of patterns and interdependencies of all kinds.

Nonsystemic gifted education typically has the goal of optimizing the components of a system (e.g., motivation, learning behavior) instead of seeking to optimize the ensemble of components at the level of their interactions. The latter goal - the hallmark of systemic gifted education — leads to a fundamentally different concept of causation, as we discuss below. Based on this different understanding of causality, we discuss consequences for the concept of giftedness and for gifted education. We introduce the two overarching aims of systemic gifted education: a remedial aim and a talent development aim. Finally, we describe the concept of a learning pathway.

\section{Circular Causation}

In contrast to nonsystemic gifted education, systemic gifted education is not a process that is mainly regulated by a gifted educator. Instead, systemic gifted education follows the principle of circular causation (Bateson, 1972; Dallos \& Draper, 2005). In an actiotope, all the components are connected to each other and effect each other in loops. Here, causation is not a linear but a circular process. The gifted educator can thus start at any point in the process. She must, however, realize that she will then become an integral part of this process.

For example, giftedness research has identified many causes of underachievement, which is defined as unexpectedly low academic achievements in relation to an individual's potential (McCoach \& Siegle, 2003). When confronted with such a problem, a systemic gifted educator would not assume that the problem is being caused by one or even several factors being out of tune. Rather, the educator working in a systemic paradigm would suspect that the entire structure of the system is dysfunctional. Low achievements might be accompanied by low interests, low aspirations, enhanced test anxiety, negative teacher expectancies, dysfunctional attributional styles for the child's achievements by the parents, and so on. The systemic paradigm thus requires a practitioner of gifted 
education to consider the whole actiotope, not just selected factors. She can build on the strategic-structural perspective developed within systemic interventions (e.g., Madanes, 1981; Minuchin \& Fishman, 1981), which is appropriate when structures in a child's actiotope seem to be dysfunctional or threaten to become dysfunctional with respect to talent development. Systemic gifted education is about providing optimal conditions for self-organizing processes of the actiotope. All components need to be returned to a homeostatic or homeorhetic state in which the components are once again synchronized in order to maintain stability (the homeostatic element) as well as adaptability (the homeorhetic element) of the actiotope to the end of talent development.

\section{The Concept of Giftedness and Gifted Identification}

As the whole actiotope is the unit of analysis in systemic gifted education, the term giftedness itself needs some modification. It has been suggested (Ziegler, 2005) that gifted persons have the potential in at least one domain of developing extraordinary action repertoires through adaptive learning processes. However, an absolute measure of giftedness does not exist. For example, the results of IQ tests simply reflect how much a person is immersed in the cultural tools necessary to solve its items. It is a measure of "proximity" to a given culture rather than of "individual strength" (Richardson, 2002). This is reflected, for example, in the lower average IQs of some ethnic minorities, people from developmental countries, or previous generations (Flynn, 2012; Steele, 2010). Similarly, the results of achievement tests indicate whether an effective action repertoire has been accrued. However, an effective action repertoire is a function of the whole actiotope and not just an indication of some vague entity such as a talent or a gift. Thus, giftedness is the attribute of an entire actiotope, which by its very nature always includes the individual and environmental components as parts of a single entity. This opens up interesting new perspectives for gifted identification in particular. For example, practitioners who follow a systemic approach might not only be interested in identifying gifted individuals but also interested in discovering learning-resources-rich environments that afford excellent learning opportunities.

\section{Two Overarching Goals of Systemic Gifted Education}

At the core of systemic gifted education are the connections among an actiotope's components and the outcomes associated with these connections. Two broad general aims can be distinguished that are specific to gifted education: the remedial aim and the talent development aim. ${ }^{2}$

The remedial aim in gifted education has two ends. First, it corrects possible maldevelopments resulting from the giftedness itself or from gifted education. For example, the labeling of a gifted student is considered by many authors as a risk factor for gifted individuals (Heller, 2004). Second, remedial gifted education is directed at keeping a system (i.e., the actiotope) operative for talent development. An example would be a gifted educator who sets new incentives for a gifted student suffering through a period of low motivation. From a systemic perspective, remedial gifted education can be broken down to three problems, which are best posed as questions:

- How can the actiotope maintain balance?

- How can the actiotope break out of an undesired balance?

- How can the actiotope regain balance?

An example of an out-of-balance actiotope is the actiotope involving a perfectionistic student who sets overly ambitious goals that exceed the competencies of her action repertoire and therefore lead to frustration. Various disorders might result from that imbalance (Guignard, Jacquet, \& Lubart, 2013). Efforts to remediate the imbalance will involve steps at reintegrating the actiotope's components in the direction of desired homeostatic or homeorhetic states. Undesired balances can take on various forms and are usually self-reinforcing cycles. It is important to note that, from a systemic perspective, any state of undesired balances should always be viewed as reflecting an individual's best attempts at solving a problem, as dysfunctional as such an attempt might seem to an observer. For example, when a student falls short of an achievement goal, her self-esteem might suffer. The averseness of a drop in self-esteem may well compel her to prioritize maintaining self-esteem over learning (Baumeister, 1997). Various defensive reactions intended to protect self-esteem can follow, such as dismissing feedback or even disengaging from school entirely (Crocker \& Luhtanen, 2003).

The talent development aim, on the other hand, is ultimately directed at acquiring highly effective action repertoires. Therefore, gifted education is a systemized method of structuring the environment in a way that optimizes development of the actiotope in the proximal zone of development (Chaiklin, 2003). The environment will be systematically arranged to offer learning experiences of increasing complexity that natural environments can no longer afford. In this process, new learning environments are created by and with other persons, and the environments are themselves nested in larger structures and learning cultures of a discipline or a domain. The actions of persons learning in such environments are in the process of becoming increasingly coordinated and harmonious as skill levels rise. Interpersonal coordination leads to stable patterns of optimizing the actiotope of a gifted individual. Teachers, mentors, parents, friends, and other stakeholders in a given actiotope are increasingly well aligned. The actiotope develops from a 
protosystem into a full-fledged system that maintains itself to the end of high achievements in a given domain.

\section{Learning Pathways}

As an actiotope develops, its breadth and depth increase. It picks up skills, resources, familiarity with relevant environmental settings, and so on, reflecting the unique action repertoires, goals, experiences, and relationships that exist only in a specific actiotope. However, many provisions in gifted education start at a more or less arbitrary point in the life of a gifted person and do not consider her background sufficiently. Talent development based on a systemic approach is a pathdependent process. This means, first, that educational decisions need to reflect not only the present state of an actiotope but also its history. Each learning step extends the previous action repertoire by new and hopefully more effective ways to act. In turn, goals as well as the subjective action space and environmental learning opportunities need to be recalibrated. Yesterday's challenge is today's normality. Hence, new challenges must be set on an ongoing basis. Second, educational decisions are path-dependent in the sense that the order of educational measures is of the utmost importance, because new challenges do not result from random processes. A nice and often cited example to illustrate this assertion is the almost self-evident fact that individuals do not learn to speak by listening to randomly ordered words. Language comes in structured patterns; hence, language development relies not simply on words but on exposure to organized patterns of sounds and words. Similarly, learning in general relies on exposure to structured activities, which usually involve other persons such as role models, teachers, and peers in cooperative learning communities. There is a permanent positive tension between educational agents (parents, teachers, coaches, etc.) who demand the mastering of cultural patterns from a less-developed individual. If the challenge is met, a new challenge is set, otherwise further talent development ceases.

The AMG introduces the concept of a learning pathway and suggests taking a long-term perspective on the development of an actiotope. Two important consequences arise. First, at each moment on a learning pathway, sufficient exogenous and endogenous resources need to be available and accessible. Second, for any possible educational action a systemic gifted educator might take, she must first consider all manner of resulting positive and negative feedback loops. For example, after a teacher has given a gifted student a homework assignment, the student might encounter an obstacle while working on the assignment at home. Teaching the student self-motivation strategies might, for example, initiate negative feedback loops that allow students to bounce back when dealing with failure.

\section{Discussion}

The overarching aim of this article was to broaden the perspective of gifted education by introducing systemic thinking. We presented arguments why systemic thinking is a valuable addition to gifted education in that it directs attention to new phenomena, new aims, and new methods. Our work of the past roughly 12 years in this area, which we have summarized in this article, also represents an attempt to question and then transcend the putative dichotomy between systemic and nonsystemic approaches to gifted education. We have emphasized throughout that reflecting on a systemic perspective can be a helpful option whenever the educational focus is on the intersection of the individual and context and a gifted educator is trying to understand individual outcomes as a product of an individual's interaction with her or his personal environment. In this case, the unit of analysis is no longer the gifted individual but rather the nexus of individual and context (Ziegler et al., 2013). This synthetic unit of analysis is called the actiotope. It is an elaboration on a proposition made by Csikszentmihalyi (1998), who located excellence not in the person but rather in the system consisting of the person and her environment. In contrast to existing approaches to giftedness, gifted education, and talent development, the AMG takes a dynamic perspective and is mostly interested how the interplay of components and their goal-directed synchronization produce actions rather than on "fixed" attributes such as gender or age that to do not vary with the environment (Bryk \& Raudenbush, 1992).

In highlighting the main contributions a systemic approach can make to gifted education, it should be emphasized first and foremost that the approach facilitates a focus on (a) individuals' interactions within their environment, (b) the patterns of interactions therein, and (c) patterns of relations within the environment that shape developmental outcomes and provide opportunities for or constraints on individual actions. With regard to talent development, gifted educators create potent trajectories of development (Ziegler \& Phillipson, 2012a). A thoroughly ordered sequence of new learning opportunities creates learning pathways that help the individual build effective action repertoires embedded in a process of coevolution of the actiotopes' components and their subsystems. The outcomes of talent development are highly dependent on the ways in which endogenous and exogenous resources support interactions of an actiotope's components and foster talent development (Ziegler, Chandler, et al., in press). It is a developmental process in which the individual learns to perform complex actions to achieve increasingly ambitious goals within given environments. If a person eventually achieves excellence, she willwell before her excellent achievements become manifest to outside observers - have already built a web of well-coordinated actions that allow her to pursue successfully a multitude of well-synchronized goals in her domain. Learning is a creative process in which the system itself acquires continuously emergent properties that transcend existing structures.

Such an approach has many consequences. We have discussed four of these consequences in this article. First, the concept of causation needs to be adapted. Due to the principle 
of circular causation, a gifted educator has to focus on the whole actiotope. Second, with regard to identification, a much more elaborated approach is needed. The process of identification cannot meaningfully be limited to the gifted individuals. It must not only touch on but be fundamentally oriented toward the quantity and quality of learning resources that systems have to offer to gifted individuals and toward the learning resources the individuals have at their disposal for making use of learning-resource-rich environments. Third, we outlined two overarching goals for gifted education that aim (a) at an operative system such as the actiotope as a precondition for (b) talent development. Fourth, we pointed out that systemic gifted education is more interested in a longterm rather than a short-term perspective designed around the creation, implementation, and long-term maintenance of a learning pathway that is rooted in a resource orientation.

Though systemic thinking can, we argue, have a stimulating effect on gifted education, there are three limitations which are important to mention. First and most evidently, a holistic approach lacks the insights one can gain with the reductionist method. In particular, when elements are not well connected, a reductionist approach is extremely valuable and obviously the more immediately appropriate approach.

Second, a systemic approach such as the AMG is not an empirical theory that can be directly tested or falsified. It is rather a paradigm or framework of theories that specifies functions. For example, the goal system is responsible for deciding which states of the system are preferred or avoided. However, it needs specific theories to explain how an individual determines the desirability of states of the system. Therefore, for a full-fledged and testable empirical theory, the AMG needs to be combined with other theories, for example, theories of emotions or of needs which have been used to explain why a person prefers some states and avoids others. Thus, depending on the point of view, one can consider a systemic model such as the AMG as intentionally incomplete, because it has to be combined with other theories. From the perspective we have presented in this article, we view this as a strength of the AMG, because a model such as the AMG offers a framework in which to integrate and understand otherwise separate and distinct theories.

The third limitation is hopefully only a temporal one. As systemic gifted education is yet in its nascent stage, many theoretical insights still await being put into practice, and this raises all manner of practical issues. For example, whereas a multitude of IQ tests has been developed and used for gifted education, only two measurement tools are available for measuring the learning resources of the gifted (Harder, Trottler, Vialle, \& Ziegler, 2015; Vladut, Vialle, \& Ziegler, 2016). Thus, educational provisions, identification tools, and practitioners of gifted education rooted in systems thinking are urgently needed. Only when more systems-theory-based approaches have been created will systemic gifted education be in a position to begin its true field test.
In concluding, it should be emphasized again that the approach presented here reflects what we deemed to be the most important additions that systems theory has to offer for gifted education. Other scholars working within a systemic paradigm would certainly have focused on other aspects. Our hope is, finally, that our remarks will further encourage the proliferation of ever more systemic models for gifted education that will complement ours and combine with leading reductionist approaches.

\section{Declaration of Conflicting Interests}

The author(s) declared no potential conflicts of interest with respect to the research, authorship, and/or publication of this article.

\section{Funding}

The author(s) received no financial support for the research, authorship, and/or publication of this article.

\section{Notes}

1. Because we use the term giftedness throughout this article, a short working definition is in order. In line with Heller (1991), we understand giftedness in the following as a potential for extraordinary achievement. However, we want to emphasize that a systemic theory in gifted education does not require a specific definition of giftedness. Rather, it is open to many definitions. Gifted education can be contrasted with the term talent development, which emphasizes developmental processes (to which, of course, gifted education can contribute).

2. Of course, a gifted educator has many more educational aims. However, as these are not unique to gifted education, they will not be considered here.

\section{References}

Bateson, G. (1972). Steps to an ecology of mind. New York, NY: Ballantine Books.

Baumeister, R. F. (1997). Esteem threat, self-regulatory breakdown, and emotional distress as factors in self-defeating behavior. Review of General Psychology, 1, 145-174. doi:10.1037/10892680.1.2.145

Brownlie, D. (1994). Environmental scanning. In M. J. Baker (Ed.), The marketing book (3rd ed., pp. 139-192). Oxford, England: Butterworth-Heinemann.

Bryk, A. S., \& Raudenbush, S. W. (1992). Hierarchical linear models: Applications and data analysis methods. Newbury Park, CA: Sage.

Chaiklin, S. (2003). The zone of proximal development in Vygotsky's analysis of learning and instruction. In A. Kozulin, B. Gindis, V. Ageyev, \& S. Miller (Eds.), Vygotsky's educational theory and practice in cultural context (pp. 39-64) Cambridge, England: Cambridge University Press.

Crocker, J., \& Luhtanen, R. K. (2003). Level of self-esteem and contingencies of self-worth: Unique effects on academic, social, and financial problems in college students. Personality and Social Psychology Bulletin, 29, 701-712. doi:10.1177/0146167203029006003

Csikszentmihalyi, M. (1998). Creativity and genius: A systems perspective. In A. Steptoe (Ed.), Genius and the mind: Studies 
of creativity and temperament (pp. 39-64). Oxford, England: Oxford University Press.

Dai, D. Y. (2009). Essential tensions surrounding the concept of giftedness. In L. V. Shavinina (Ed.), International handbook on giftedness (pp. 39-80). New York, NY: Springer.

Dallos, R., \& Draper, R. (2005). An introduction to family therapy: Systemic theory and practice. London, England: Open University Press.

Flynn, J. R. (2012). Are we getting smarter? Rising IQ in the twentyfirst century. Cambridge, England: Cambridge University Press.

Guignard, J. H., Jacquet, A. Y., \& Lubart, T. I. (2013). Perfectionism and anxiety: A paradox in intellectual giftedness? PLOS ONE, 7(7), e41043. doi:10.1371/journal.pone.0041043

Harder, B., Trottler, S., Vialle, W., \& Ziegler, A. (2015). Diagnosing resources for effective learning via teacher and parent checklists. Psychological Test and Assessment Modeling, 57, 201221.

Heller, K. A. (1991). The nature and development of giftedness: A longitudinal study. European Journal for High Ability, 2, 174188. doi:10.1080/0937445910020207

Heller, K. A. (2004). Identification of gifted and talented students. Psychology Science, 46, 302-323.

Jones, G. (2012). The role of superior performance intelligence in sustained success. In S. M. Murphy (Ed.), The Oxford handbook of sport and performance psychology (pp. 62-80). New York, NY: Oxford University Press. doi:10.1093/oxfor dhb/9780199731763.013.0004

Luenberger, D. G. (1979). Introduction to dynamic systems: Theory, models, and applications. New York, NY: Wiley.

Madanes, C. (1981). Strategic family therapy. San Francisco, CA: Jossey-Bass.

Matthews, M. S. (2009). Gifted learners who drop out: Prevalence and prevention. In L. V. Shavinina (Ed.), International handbook on giftedness (pp. 527-536). New York, NY: Springer.

McCoach, D. B., \& Siegle, D. (2003). Factors that differentiate underachieving gifted students from high-achieving gifted students. Gifted Child Quarterly, 47, 144-154. doi:10.1177/001698620304700205

Michel, A., Wang, K., \& Hu, B. (2001). Qualitative theory of dynamical systems. London, England: Taylor \& Francis.

Miller, G. A., Galanter, E., \& Pribram, K. H. (1960). Plans and the structure of behavior. New York, NY: Holt.

Minuchin, S., \& Fishman, H. C. (1981). Family therapy techniques. Cambridge, MA: Harvard University Press.

Nisbett, R. E. (2003). The geography of thought: How Asians and Westerns think differently and why. London, England: Nicholas.

Overton, W. F. (2013). Relationism and relational developmental systems: A paradigm for developmental science in the postCartesian era. Advances in Child Development and Behavior, 44, 21-64.

Pekrun, R., Lichtenfeld, S., Marsh, H. W., Murayama, K., \& Goetz, T. (2017). Achievement emotions and academic performance: Longitudinal models of reciprocal effects. Child Development. Advance online publication. doi:10.1111/cdev.12704

Piaget, J. (1960). Equilibration and development of logical structures. In J. M. Tanner \& B. Inhelder (Eds.), Discussions on child development (Vol. 4, pp. 98-115). New York, NY: International Universities Press.

Renzulli, J. S. (1986). The three-ring conception of giftedness: A developmental model for creative productivity. In R. J. Sternberg \& J. E. Davidson (Eds.), Conceptions of giftedness (pp. 53-92). New York, NY: Cambridge University Press.

Richardson, K. (2002). What IQ tests test. Theory and Psychology, 12, 283-314. doi:10.1177/0959354302012003012

Richardson, K. (2013). The evolution of intelligent developmental systems. In R. M. Lerner \& J. B. Benson (Eds.), Embodiment and epigenesist: Theoretical and methodological issues in understanding the role of biology within relational developmental systems (pp. 127-160). Amsterdam, Netherlands: Elsevier.

Simonton, D. K. (2005). Giftedness and genetics: The emergentic-epigenetic model and its implications. Journal for the Education of the Gifted, 28, 270-286. doi:10.4219/jeg-2005338

Steele, C. M. (2010). Whistling Vivaldi and other clues to how stereotypes affect us. New York, NY: Norton.

Sternberg, R., \& Davidson, J. (2005). Conceptions of giftedness. Cambridge, England: Cambridge University Press.

Thelen, E., \& Smith, L. B. (1994). A dynamic systems approach to the development of cognition and action. Cambridge: MIT Press.

Vladut, A., Vialle, W., \& Ziegler, A. (2016). Two studies of the empirical basis of two learning resource-oriented motivational strategies for gifted educators. High Ability Studies, 27, 39-60. doi:10.1080/13598139.2016.1212702

von Bertalanffy, L. (1975). Perspectives on general system theory: Scientific-philosophical studies. New York, NY: George Brazilier.

Ziegler, A. (2005). The actiotope model of giftedness. In R. Sternberg \& J. Davidson (Eds.), Conceptions of giftedness (pp. 411-434). Cambridge, England: Cambridge University Press.

Ziegler, A., \& Baker, J. (2013). Talent development as adaption: The role of educational and learning capital. In S. Phillipson, H. Stoeger, \& A. Ziegler (Eds.), Exceptionality in East Asia: Explorations in the actiotope model of giftedness (pp. 18-39). London, England: Routledge.

Ziegler, A., Chandler, K., Vialle, W., \& Stoeger, H. (in press). Exogenous and endogenous learning resources in the actiotope model of giftedness and its significance for gifted education. Journal for the Education of the Gifted.

Ziegler, A., \& Phillipson, S. (2012a). Exceptionality and gifted education: A re-examination of its hard core. High Ability Studies, 23, 133-142. doi:10.1080/13598139.2012.736221

Ziegler, A., \& Phillipson, S. (2012b). Towards a systemic theory of giftedness. High Ability Studies, 23, 3-30. doi:10.1080/135981 39.2012.679085

Ziegler, A., Stoeger, H., \& Balestrini, D. (in press). Systemic gifted education. In C. O’Reilly, T. Cross, \& J. Riedl Cross (Eds.), Provisions for gifted students. Dublin, Ireland: CTYI Press.

Ziegler, A., Vialle, W., \& Wimmer, B. (2013). The actiotope model of giftedness: A short introduction to some central theoretical assumptions. In S. Phillipson, H. Stoeger, \& A. Ziegler (Eds.), Exceptionality in East Asia: Explorations in the actiotope model of giftedness (pp. 1-17). London, England: Routledge. 


\section{Author Biographies}

Albert Ziegler, $\mathrm{PhD}$, is chair professor of educational psychology and research on excellence at the University of Erlangen-Nuremberg, Germany. He is the founding director of the Statewide Counselling and Research Centre for the Gifted. He has published approximately 300 books, chapters, and articles in the fields of talent development, excellence, educational psychology, and cognitive psychology. Presently, he serves as the secretary general of the International Research Association for Talent Development and Excellence, as vice president of the European Council for High Ability, as chairman of the European Talent Support Network, and as editor-in-chief of High Ability Studies.
Heidrun Stoeger, $\mathrm{PhD}$, is full professor for educational sciences at the University of Regensburg, Bavaria, Germany. She holds the chair for school research, school development, and evaluation. She is vice president of the International Research Association for Talent Development and Excellence. She is also member of the editorial board of the German Journal of Talent Development and was editor-in-chief of the journal High Ability Studies (2007-2014). She has published more than 200 articles, chapters, and books on giftedness, self-regulated learning, motivation, fine motor skills, and teacher education. She is member of several national and international scientific boards and expert commissions in the field of giftedness research and gifted education. 